\title{
Comparative Dissolution and Disintegration Study of Different Brands of Linezolid 600 mg Tablets Available in Karachi, Pakistan
}

\section{Uddin AS*}

Department of Pharmaceutics, Federal Urdu University of Arts Sciences and Technology, Gulshan lqbal, karachi, Pakistan

\begin{abstract}
The dissolution and disintegration tests (USP) are extensively useful for the determination of the safe and effective drugs as well as used for the stability and quality of the drug product. The purpose of the study was to observe the disintegration and dissolution profile (UV spectrophotometer), and estimation of the quality through weight variation and hardness test of different brands of Linezolid $600 \mathrm{mg}$ tablets from Karachi, Pakistan. The weight variation test for all the brands was found to be under normal limits and the hardness of all the brands was also within normal limits. The tablet disintegration time was as per the specifications and all the tablets were disintegrated within 30 minutes except for brand $\mathrm{C} 3$, which disintegrates within 3.98 minutes and provided better disintegration time. Although, all the brands showed better dissolution rate, but the percent drug release of $\mathrm{C} 1$ was found to be the best, i.e. $100 \%$ drug was dissolved in 30 minutes in contrast to the different brands. Dissolution test is comparatively an efficient and cost effective in vitro approach that can be helpful in the assessment of the release attributes of formulation. It was found that brand $\mathrm{C} 1$ and $\mathrm{C} 2$ exhibited better dissolution profile as compared to other brands. Although, $\mathrm{C} 3$ and $\mathrm{C} 4$ were also found to be under the limits i.e. $80 \%$ of the label amount of the drug.
\end{abstract}

Keywords: Linezolid; Spectrophotometer; Pneumonia; WHO

\section{Introduction}

Linezolid is very renowned synthetic antibacterial compound of the oxazolidinone derivatives and very helpful to treat Vancomycinresistant Enterococcus faecium infections; Nosocomial pneumonia; complicated skin and skin structure infections including diabetic foot infections, without concomitant osteomyelitis; uncomplicated skin and skin structure infections and community acquired pneumonia. Linezolid should be taken two to three times per day [1].

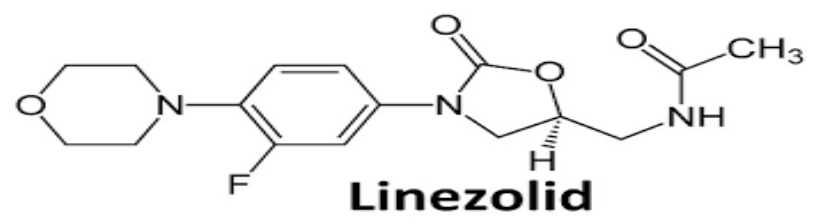

Linezolid is reversible, nonselective inhibitor of monoamine oxidase. Therefore, Linezolid has the potential for interaction with adrenergic and serotonergic agents [2]. Basically Linezolid is completely a synthetic substance, which minimizes the tendency of naturally occurring resistance mechanisms. Linezolid has greater strength against grampositive pathogens, including methicillin-resistant staphylococci, penicillin-resistant pneumococci, macrolides-resistant streptococci, and vancomycin-resistant enterococci. It was observed that the bioavailability of Linezolid (orally) is almost $100 \%$ so it can be taken orally or intravenously. Linezolid compound is permitted against various infections of skin and soft tissue; lower respiratory tract infections; and vancomycin-resistant Enterococcus faecium infections, including cases with concurrent bacteremia. Linezolid compound showed suitable portfolio of side effects, but on the other hand few patients, who take high doses beyond two weeks resulting reversible myelosuppression [3].

\section{Absorption}

Linezolid have fast absorption after oral dosing. Maximum plasma concentrations attained almost in one to two hours after dosing and the absolute bioavailability is almost $100 \%$.

\section{Metabolism}

Initially Linezolid is metabolized by the morpholine ring oxidation and dual inactive metabolites are produced; i-aminoethoxyacetic acid metabolite, ii-thehydroxyethyl glycine metabolite. The hydroxyethyl glycine metabolite is produced by non-enzymatic chemical oxidation mechanism in vitro [4]. Linezolid never metabolized in terms of significant with cytochrome p450 (CYP) enzyme and neither suppress CYP isoenzymes and is not an enzyme inducer, revealed that the drug is rarely alter the pharmacokinetics of drugs metabolized by these enzymes (McEvoy).

\section{Elimination}

Basically linezolid is eliminated through urine with steady state situations in terms of PNU-142586 (40\%), parent drug (30\%) and PNU-142300 (10\%). Practically in stool there is no patent drug is present and at the same time almost 6\% (PNU-142586) and 3\% (PNU142300) of individual dose emerges. Generally, Linezolid elimination half-life is around 5-7 hours. Linezolid, non-renal clearance reported for almost $65 \%$ of the total clearance. By enhancing doses of linezolid a very minute intensity of non-linearity in terms of clearance was noted. This happens because of lower renal and non-renal clearance at greater linezolid strengths.

*Corresponding author: Akif Syed Uddin, Department of Pharmaceutics, Federa Urdu University of Arts Sciences and Technology, Gulshan lqbal, karachi, Pakistan, Tel: 00923343525386; E-mail: akifsyed30@yahoo.com

Received November 27, 2018; Accepted December 21, 2018; Published December 27, 2018

Citation: Uddin AS (2018) Comparative Dissolution and Disintegration Study of Different Brands of Linezolid 600 mg Tablets Available in Karachi, Pakistan. Pharm Anal Acta 9: 602. doi: 10.4172/2153-2435.1000602

Copyright: (c) 2018 Uddin AS. This is an open-access article distributed under the terms of the Creative Commons Attribution License, which permits unrestricted use, distribution, and reproduction in any medium, provided the original author and source are credited. 


\section{Toxicity}

The basic harmful effect of Linezolid is reversible hematologic which is commonly mild. Commonly indication which was observed almost with three per cent of patient courses is Thrombocytopenia especially if Linezolid is used for more than 14 days. The other harmful effect like Anaemia, neutropenia can take place in that patient who suffer with bone marrow suppression. Research of optic and peripheral neuropathy and lactic acidosis revealed adverse effects by the increase usage of linezolid like mitochondrial protein synthesis suppression. It is observed that combination of linezolid taken with serotogenic drugs (e.g. selective serotonin reuptake inhibitor) resulting serotonin syndrome developed [5].

\section{Literature review}

Nine formulations of Immediate Release Tablets of Linezolid were prepared with wet granulation technique using different disintegrants to achieve expected release according to the standards. They also studied different quality control aspects which were all within the limits [6]. Different immediate-release of BCS Class I drugs i.e. fluoxetine and linezolid and a Class III drug i.e. fluconazole generic drugs pursue the necessity of $85 \%$ or further release of drug in 15 or $30 \mathrm{~min}$ in various buffers i.e. $\mathrm{pH} 1.2, \mathrm{pH} 4.5$, and $\mathrm{pH} 6.8$ with in vitro dissolution observation as per WHO. The two drugs i.e. Fluoxetine and Linezolid follow the specifications of biowaiver for BCS Class I drugs and can show in vitro equivalency, although fluconazole cannot accomplish the specifications of the protocols of WHO with respect to in vitro equivalency [7]. Dissolution test is comparatively an efficient and cost effective in vitro approach that can be helpful in the assessment of the release attributes of formulation as well as very effective in vitro assessment that can be used to asses and control variables relationship with formulation excipients, design and manufacturing [8]. So it is important to perform the dissolution test in order to forecast better in vivo evaluation of the drug product, which would be obtained if the gastrointestinal tract environment rejuvenates in vitro in better way [9]. In vitro dissolution depends upon the nature of the product, manufacturing technique and physicochemical properties of drug [10]. As $40 \%$ of compounds are lipophilic, so creating problem in dissolution. So, for this purpose FDA has published recommendations for single point dissolution and multipoint dissolution studies to evaluate immediate and modified release formulations [11].

\section{Weight variation}

Weight variation test is carried out to observe that the manufactured tablets have uniform weight (Babu). Weight variation test always describes that individual tablet of whole batch consists of accurate quantity of drugs (Reddy). This test is done to assure uniformity in the weight of tablets because variation in weight of tablets can cause difference in doses. So each tablet of a batch must be observed by weight variation test. Twenty tablets are selected randomly and their average weight is calculated [12]. For a tablet to pass the test not more than 2 tablets should lie out of the specified percentage and if no tablet differs by more than two times the percentage limit [13]

\section{Procedure}

From each brand twenty tablets were selected randomly and their weight was taken individually. The average weight was calculated and the results were tabulated on Microsoft Excel.

\section{Hardness}

Hardness is also referred to as crushing strength. Hardness of tablet is a very vital tool to observe the strength of splitting a tablet in a diametric compression test. Hardness can affect the disintegration [14]. With respect to the composition of tablets, including active ingredient, it is very essential to note down the precise tablet hardness [15]. Before discarding any tablet, if it is too soft or hard, then disintegration test must be performed. If the results are under the specified limits then the product can be approved. Hardness is very essential parameter in tablets because it estimates the capability of tablets to tolerate the impact of handling, packing and shipping or transportation [14].

\section{Procedure}

Ten tablets were selected randomly from each brand and their average hardness was calculated. The results were tabulated and analyzed graphically using Microsoft Excel 2016. The results should be within acceptable limits, i.e., 6-10 kg.

\section{Disintegration test}

"Disintegration is a fundamental demand of tablet to convert it into small particles thereby increasing the drug's surface area, which is very much vital for gastrointestinal absorption (GI)". Disintegration of tablets is very essential to classify the dissolution rate and many researchers revealed disintegration as a surrogate for dissolution [16]. The disintegration test is very advantageous to estimate disintegration of tablets or capsules within specified time when interact with a solvent which is according to standards [17]. In this method, six tablets from each batch are placed in each of the six tubes of the basket, immersed in appropriate medium and disintegration time is noted, which should be under the specified limits given in pharmacopeias. Disintegration of tablets has significant aspects throughout the production process. The greater powerful in vitro framework is to develop an indicator of drug bioavailability focused on disintegration. The first definite disintegration method was printed in the United States Pharmacopoeia [8]. The process of disintegration is renowned for the mechanical splitting of a compressed tablet into tiny granules and it is classified by the splitting of the interparticulate bonds, meanwhile counterfeit at the time of tablet compaction [18]. Tablet disintegration is an essential aspect in terms of drug release and altered by non-active ingredients known as disintegrants. These disintegrants provide various actions and the effectiveness of these disintegrants can be affected by many factors [19].

\section{Methodology}

$0.6 \% \mathrm{v} / \mathrm{v}$ solution of $\mathrm{HCl}$ was prepared $(16.2 \mathrm{ml}$ of $37 \% \mathrm{HCl}$ into $500 \mathrm{ml}$ of distilled water and the volume was made up to $1000 \mathrm{ml}$ with distilled water) and the vessel of disintegration test apparatus was filled with this solution up to the suggested point. The temperature was adjusted at $35^{\circ} \mathrm{C}$ and $39^{\circ} \mathrm{C}$. One tablet was placed in each of the six tubes of the basket. The time was noted with the help of stop watch. All the tablets must be disintegrated within 30 minutes according to USP 2007 standards (Table 1, Figures 1 and 2).

\section{Dissolution test}

It is the most important quality control test, which determines the rate of release of the active ingredient from the drug product [8] The strategy of drug characterization of bio pharmaceutics with the association of in vitro drug product dissolution and suggested in vivo bioavailability depend upon that dissolution of drug and permeability of GI are the basic tool to control the rate and extent of the absorption of drug [20]. The dissolution observation in pharmaceutical world can play as effective mechanism to manufacture and develop a quality drug. The basic perception and significance to observe the dissolution of oral solid dosage type will be useful for the observation of in vitro / drug release for special dosage forms [21]. Physico-chemical deviations 
Citation: Uddin AS (2018) Comparative Dissolution and Disintegration Study of Different Brands of Linezolid 600 mg Tablets Available in Karachi, Pakistan. Pharm Anal Acta 9: 602. doi: 10.4172/2153-2435.1000602

Page 3 of 4

\begin{tabular}{|c|c|c|c|}
\hline S. No. & Weight $\mathbf{( m g )} \mathbf{~ N = 5}$ & Hardness $\mathbf{( k g ) ~} \mathbf{N = 5}$ & $\begin{array}{c}\text { Disintegration } \\
(\mathbf{m i n}) \mathbf{N = 5}\end{array}$ \\
\hline C1 & $948.52 \pm 6.21$ & $9.51 \pm 0.09$ & $3.16 \pm 0.18$ \\
\hline C2 & $854.46 \pm 4.90$ & $11.21 \pm 0.02$ & $3.38 \pm 0.14$ \\
\hline C3 & $796.48 \pm 5.14$ & $13.31 \pm 0.20$ & $3.98 \pm 0.14$ \\
\hline C-4 & $812.56 \pm 2.91$ & $8.22 \pm 0.25$ & $3.46 \pm 0.22$ \\
\hline
\end{tabular}

Table 1: Weight and hardness of linezolid tablet $600 \mathrm{mg}$.

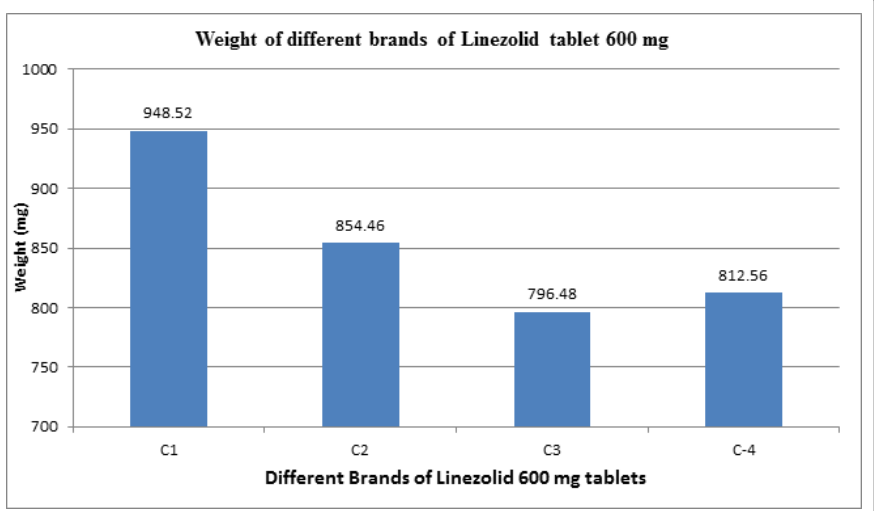

Figure 1: Weight of different brands of linezolid tablet $600 \mathrm{mg}$

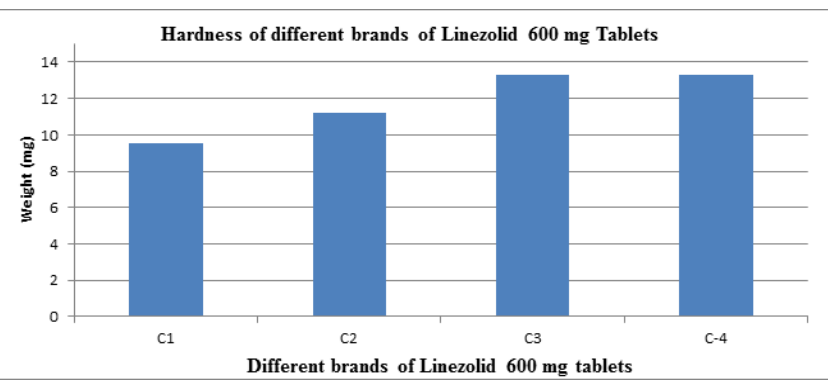

Figure 2: Hardness of different brands of linezolid tablet $600 \mathrm{mg}$

like particle size diversity, excessive amounts of lubricant and coatings are reactive to dissolution testing therefore, dissolution tests are much essential in perceptive between batches of drug product(s) [8].

\section{Equipment}

Dissolution Apparatus II (ERWEKA, DT, Heusenstamm Germany), UV/VIS Detector (Shimadzu Corp., Japan), Linezolid Standard, Linezolid Tablets (Test) Different Pharmacies in Karachi, Pakistan.

Standard stock solution: $22 \mathrm{mg}$ of Linezolid was accurately weighed in $100 \mathrm{ml}$ volumetric flask. It was dissolved by adding approx. 40 to $60 \mathrm{ml}$ of diluents. The mixture was shaken for 5 minutes. The volume was made up with diluents.

Working standard: $3 \mathrm{ml}$ volumetric pipette was taken and rinsed with standard stock solution. Quantitatively $3 \mathrm{ml}$ of standard stock solution was transferred in a $50 \mathrm{ml}$ volumetric flask and the volume was made up with diluents up to mark and was shaken well.

Experimental condition: Dissolution medium: $0.1 \mathrm{~N} \mathrm{HCl}$, Time: 30 minutes, Temperature: $37^{\circ} \mathrm{C}$ Apparatus: USP II Paddle, RPM: 100 $\mathrm{RMP} \pm 4$.

Procedure: $900 \mathrm{ml}$ of $0.1 \mathrm{~N}$ of $\mathrm{HCl}$ was taken in a cylinder of 1000 $\mathrm{ml}$ and transferred in dissolution vessels at $37^{\circ} \mathrm{C} \pm 0.5^{\circ} \mathrm{C}$. Each tablet was taken in each vessel and the apparatus was operated for 30 minutes (100 $\mathrm{rpm}$ ). At the specified times, $20 \mathrm{ml}$ of sample was withdrawn and filtered

\begin{tabular}{|c|c|c|c|c|}
\hline $\begin{array}{c}\text { Time } \\
(\mathbf{m i n})\end{array}$ & C-1 & C-2 & C-3 & C-4 \\
\hline 0 & 0.00 & 0.00 & 0.00 & 0.00 \\
\hline 5 & $79.66 \pm 0.59$ & $80.51 \pm 0.23$ & $71.16 \pm 0.25$ & $69.94 \pm 0.16$ \\
\hline 10 & $89.85 \pm 0.76$ & $83.48 \pm 0.64$ & $78.54 \pm 0.52$ & $77.60 \pm 1.04$ \\
\hline 15 & $93.78 \pm 0.39$ & $85.80 \pm 0.32$ & $83.84 \pm 0.8$ & $80.81 \pm 0.93$ \\
\hline 20 & $95.56 \pm 0.48$ & $88.94 \pm 0.89$ & $85.03 \pm 0.69$ & $88.17 \pm 1.27$ \\
\hline 25 & $97.68 \pm 0.88$ & $93.69 \pm 0.76$ & $91.88 \pm 2.05$ & $94.27 \pm 1.25$ \\
\hline 30 & $99.55 \pm 0.38$ & $99.66 \pm 0.57$ & $97.39 \pm 1.03$ & $98.94 \pm 0.95$ \\
\hline 40 & $100.66 \pm 0.47$ & $100.3 \pm 0.60$ & $98.33 \pm 0.57$ & $99.32 \pm 0.56$ \\
\hline 45 & $102.29 \pm 0.51$ & $97.41 \pm 1.56$ & $99.66 \pm 0.57$ & $99.83 \pm 0.19$ \\
\hline 60 & $103.03 \pm 0.06$ & $99.89 \pm 0.78$ & $101.66 \pm 0.57$ & $99.90 \pm 0.16$ \\
\hline 90 & $103.8 \pm 0.33$ & $100 \pm 1.11$ & $102.25 \pm 0.66$ & $100.66 \pm 1.52$ \\
\hline 120 & $104.36 \pm 1.09$ & $101.78 \pm 1.61$ & $105 \pm 1.00$ & $100.96 \pm 0.04$ \\
\hline
\end{tabular}

Table 2: Dissolution profile of different brands of linezolid $600 \mathrm{mg}$ tablets at 0.1 $\mathrm{N} \mathrm{HCl}$.

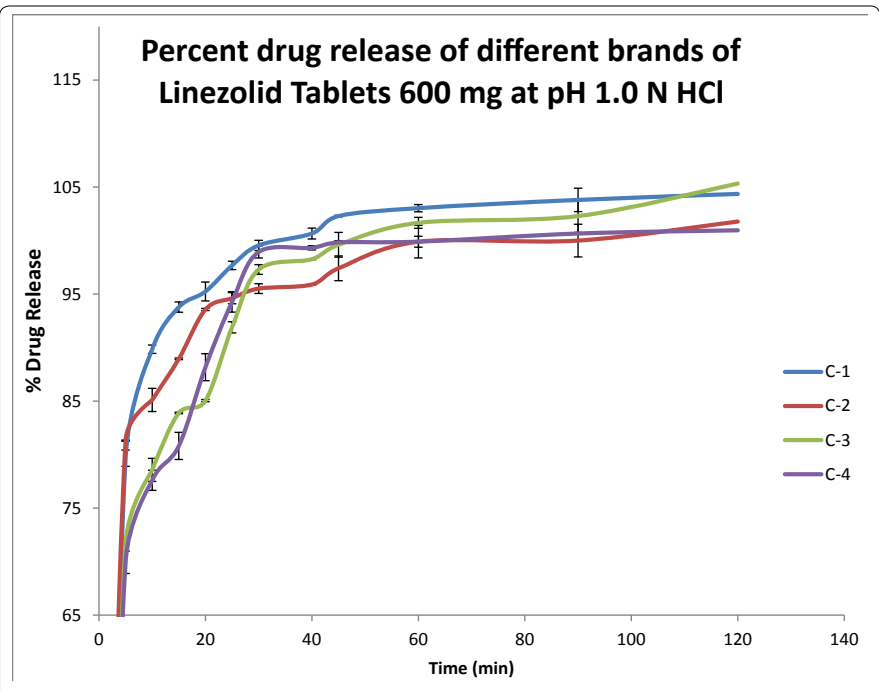

Figure 3: Percent drug release of different brands of Linezolid Tablets $600 \mathrm{mg}$ $\mathrm{pH} 1.0 \mathrm{~N} \mathrm{HCl}$.

through whattman filter paper. The mixture was then transferred in 100 $\mathrm{ml}$ volumetric flask and the volume was made up with the medium. The absorbance of working standard and sample solution was observed at $243 \mathrm{~nm}$ (Table 2 and Figure 3).

\section{Result and Discussion}

Disintegration of tablets has significant aspects throughout the production process. The greater powerful in vitro framework is to develop an indicator of drug bioavailability focused on disintegration. The first definite disintegration method was printed in the United States Pharmacopoeia [8]. The study performed by Vijaysinh. Chauhan et al., by preparing the taste masked tablet with Eudragit that disintegrates easily through microspheres forms of Linezolid and to prepare mouth disintegrating tablets of the formulated microspheres with superdisintegrant like sodium starch glycolate and sodium caramellose [22]. The tablets disintegration time was as per the specifications and all the tablets were disintegrated within 30 minutes except for brand $\mathrm{C} 1$, which disintegrates within 3.6 minutes and provided better disintegration time. Dissolution method is very effective in vitro assessment that can be used to asses and control variables relationship with formulation excipients, design and manufacturing. Pharmaceutical industries carry out the dissolution test for different purposes, for example the development of new entities, the quality control test in order to support the estimation of bioequivalence. The modern regulatory developments in which the Bio pharmaceutics Classification Scheme 
Citation: Uddin AS (2018) Comparative Dissolution and Disintegration Study of Different Brands of Linezolid 600 mg Tablets Available in Karachi, Pakistan. Pharm Anal Acta 9: 602. doi: 10.4172/2153-2435.1000602

Page 4 of 4

(BCS) has emphasized the dissolution significance in the regulation of changes after the approval and utilizing the dissolution testing for clinical studies in some cases. For orally administered immediate drugs and other solid dosage forms, the dissolution test is very important, because the drug has to be dissolved in the dissolution medium very rapidly [23]. Multiple point dissolution was carried out for different brands of Linezolid $600 \mathrm{mg}$ tablets and percent drug release was observed for every brand. It was found that brand $\mathrm{C} 1$ and $\mathrm{C} 2$ exhibited better dissolution profile as compared to other brands. Although, the other brands, C3, C4 and C5 were also found to be under the limits, i.e. $80 \%$ of the labelled amount of the drug dissolved in 30 minutes. No significant difference was observed.

\section{Conclusion}

The results indicate that all the brands of Linezolid tablets $600 \mathrm{mg}$ showed good overall quality and also the high dissolution rate shows that the drug is effectively bioavailable. It is concluded that in attempts of performing different tests, the overall result is satisfactory indicating that the proposed study is precise and accurate and can be used for the determination of Linezolid in tablet dosage forms.

\section{References}

1. Navale SV, Dabre RS, Singla AK, Tarun V (2007) Tablets of linezolid form iii and processes for their preparation. Google Patents.

2. Wade KC, Benjamin DK (2011) Clinical pharmacology of anti-infective drugs. In: Infectious Diseases of the Fetus and Newborn, pp. 1160-121.

3. Moellering RC (2003) Linezolid: the first oxazolidinone antimicrobial. Ann Intern Med 138: 135-142.

4. http://truvenhealth.com/Products/Micromedex

5. Katzung BG, Masters SB, Trevor AJ (2012) Basic and clinical pharmacology. $\left(12^{\text {th }}\right.$ edn $)$, Lange Medical Publications.

6. Reddy KSM, Sahoo L, Reddy GK, Krishna LV (2011) Formulation and evaluation of immediate release tablets of linezolid. International Journal of Pharmaceutical \& Biological Archive 2.

7. Helmy SA, Bedaiwy HM (2016) In vitro dissolution similarity as a surrogate for in vivo bioavailability and therapeutic equivalence. Dissoln Technol 8: 32-39.

8. http://apps.who.int/phint/en/p/docf/
9. Dressman JB, Amidon GL, Reppas C, Shah VP (1998) Dissolution testing as a prognostic tool for oral drug absorption: Immediate release dosage forms. Pharm Res 15: 11-22.

10. Augsburger LL, Shangraw RF, Giannini RP, Shah VP, Prasad VK, et al. (1983) Thiazides VIII: Dissolution Survey of marketed hydrochlorothiazide tablets. J Pharm Sci 72: 876-881.

11. Rudman A, Lesko L, Malinowski H, Roy S, Williams RL (1996) Guidance for industry-immediate-release solid oral dosage forms/scale-up and postapproval changes: chemistry, manufacturing, and controls; in vitro dissolution testing; in vivo bioequivalence. Pharm Tech 20: 50-79.

12. Gupta AK(2008) Introdution to pharmaceutics-i. paper back english CBS Pub. \& Dist., New Delhi.

13. Mohanachandran PS, Krishna Mohan PR, Saju F, Bini KB, Babu B, et al. (2010) Formulation and evaluation of mouth dispersible tablets of amlodipine besylate. Int J Appl Pharma 2: 1-6.

14. Bacalso BT, Baon M, Cano L (2014) Tablet hardness, thickness and diameter test.

15. Smith DJ (1985) Tablet hardness tester.

16. Scheuerle RL, Gerrard SE, Kendall RA, Tuleu C, Slater NK, et al. (2015) Characterising the disintegration properties of tablets in opaque media using texture analysis. Int J Pharm 486: 136-143.

17. Zuo J, Gao Y, Almukainzi M, Löbenberg R (2013) Investigation of the disintegration behavior of dietary supplements in different beverages. Dissoln Technol 20: 6-10.

18. Markl D, Zeitler JA (2017) A review of disintegration mechanisms and measurement techniques. Pharm Res 34: 890-917.

19. Quodbach J, Kleinebudde P (2016) A critical review on tablet disintegration Pharm Dev Technol 21: 763-774.

20. Amidon GL, Lennernäs H, Shah VP, Crison JR (1995) A theoretical basis for a biopharmaceutic drug classification: the correlation of in vitro drug product dissolution and in vivo bioavailability. Pharm Res 12: 413-420.

21. Shah VP, Siewert M, et al. (2002) Dissolution/in vitro release testing of specia dosage forms. Dissoln Technol 9: 1-5.

22. Chauhan VV, Puranik SB (2015) Formulation and evaluation of linezolid microspheres: An approach for taste masking through mouth disintegrating tablets. IJPPR 2: 177-187.

23. Siewert M, Dressman J, Brown CK, Shah VP (2003) FIP/AAPS guidelines to dissolution/in vitro release testing of novel/special dosage forms. AAPS PharmSciTech 4: 43-52. 